\title{
Resilient Drinking Water Resources
}

\author{
Ritsche A. Kloosterman ${ }^{1}$ (D) Jan Peter van der Hoek ${ }^{2}$ (D) Paulien Herder $^{2}$ (D)
}

Received: 30 April 2020 / Accepted: 2 December 2020/ Published online: 11 December 2020

(C) The Author(s) 2020

\begin{abstract}
A significant challenge for managers of drinking water infrastructures is to make effective strategic decisions for assets with a long lifetime in an uncertain and changing environment. Water resources, which are part of the drinking water infrastructures, have a special position in this decision making process as they operate at the interface of the socio-technical and the socio-ecological subsystems: water resources are the input for the technical system, consisting of pipes and pumps that interact with different actors; and water resources can be seen as output from the ecological system which is influenced by environmental and political issues like climate change, drought and competing and changing uses of water and space. This paper discusses how to design the water resources in such a way that they function in the desired way at present, but that the design also fits an uncertain future as good as possible. To this extent, a framework was developed based upon the notion of resilience. Existing general design principles for socio-technical systems from literature were used as building blocks in the development of our water resources design principles (WR-DP) framework. Three key characteristics of water resources were distinguished in this framework: water quantity, water quality and the environmental impact of the water resources. In addition, we distinguished two dimensions that allowed us to explicitly describe all possible design principles: system scale and class. The first dimension, system scale, ranges from one water resource to a network of water resources. The second dimension, class, makes a distinction between social aspects and technical aspects. Application of the WR-DP framework in a case of a drinking water company in the Netherlands showed the usability of the framework.
\end{abstract}

Keywords Drinking water infrastructures $\cdot$ Water resources $\cdot$ Resilience $\cdot$ Strategic decisions . Socio-technical system $\cdot$ Socio-ecological system $\cdot$ Long term planning

\section{Introduction}

The drinking water infrastructure (DWI) is a critical societal infrastructure that provides the essential service of drinking water supply (Doorn et al. 2019). Pipes, water resources and other

Ritsche A. Kloosterman

rian.kloosterman@vitens.nl

Extended author information available on the last page of the article 
assets of DWIs can have life times up to 100 years and during that period the desired services of DWIs and the functioning of DWIs can change dramatically due to demographic changes, changes in the way drinking water is used, economic changes, climate change etc. Assets of DWI are capital intensive and it takes a long period to develop new assets, mainly due to investigations about the suitability of the water resources, environmental impact studies and procedures to get the licenses. For example, developing a new ground water resource takes about 15 years in the Netherlands. It is a challenge for DWI managers to plan DWIs that have to be suitable now, but also in the future, even after 100 years.

DWIs can be characterised as complex, socio-technical systems (STS) as they consist of a technical network and a plethora of actors, operating under uncertainty (Kloosterman and van der Hoek 2019) (Herder et al. 2008).

Technical assets include pipes, treatment plants and pumps, with the objectives to extract water from water resources, treat this water and transport the treated water to customers. Actors associated with DWIs are, among others, technical operators who manage the process of the production and distribution of drinking water, managers who take investment decisions and set operational standards, external regulators who control the quality of services and set quality requirements, and customers who make demands on the quality and quantity of the drinking water.

Feeding into this socio-technical network is water from various water resources (WRs). The WRs include surface water from rivers and lakes, and groundwater. The way in which natural water resources are used and governed by different actors, is often conceptualised and studied through the lens of socio-ecological systems (Bowd et al. 2015) (Ostrom 2015) (Ostrom 2007) (Ostrom et al. 2006).

WRs, therefore, operate at the interface between two subsystems: The social-technical system (STS) and the social-ecological system (SES). WRs connect the STS and SES and complex interdependencies between the SES and STS have to be managed (Agusdinata and DeLaurentis 2008), (Walker 2000), (Bruijn and Herder 2009), (Bauer and Herder 2009).

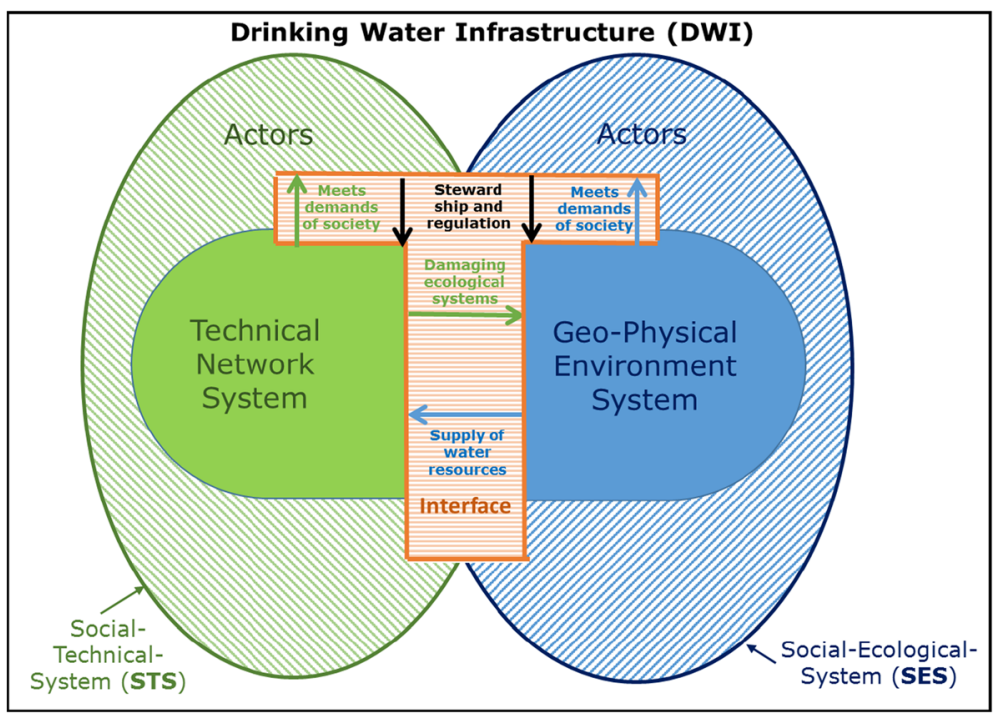

Fig. 1 Drinking water infrastructure, with water resources at the interface of STS and SES (Kloosterman and van der Hoek 2019) 
The DWI and the interactions between the STS and the SES are presented in Fig. 1. The function of the STS is to meet the needs of society and for that the STS relies on resources from the SES. Social stewardship and regulation are necessary to avoid damage and to protect vulnerable parts of the SES (La Loggia and Puleo 2020) (Markolf et al. 2018).

In the past when cities needed drinking water, they used WRs close to the city (de Moel et al. 2004), but this may not be the best choice when a city grows and the drinking water demand increases. Very often DWI companies of different cities merged and the combination of all the WRs of the different DWIs was not the optimal situation for the new consolidated DWI company (Vitens 2016).

Due to changes in the economic situation and the population, the volume of water that needs to be extracted from the WRs, now and in the future, may change. Extractions from the WRs also have a dynamic character due to seasonal and diurnal patterns. On the other hand, the amount of water that can be extracted from WRs may change due to for example climate change or changes in acceptable environmental impact (Mehrazar et al. 2020) (Minabadi et al. 2020). This makes DWIs vulnerable to changes in the WRs with respect to capacity and location of the WRs. If there is only one WR and the capacity decreases dramatically, the whole DWI is affected by this change (Vitens 2016), (de Moel et al. 2004). Therefore, smart balancing between demand (rooted in the STS) and supply (rooted in the SES), that gives a suitable solution under changing circumstances, is very complex.

The goal of this study is to support strategic decision making for WRs by developing a set of design principles. The strategic decisions have to be effective at present and in the future to ensure the long-term reliability of the water supply. Other objectives, like improving sustainability, improving efficiency or improving affordability are also important for a DWI company, but have already been addressed by other authors (Guidotti et al. 2016) (Hollnagel et al. 2010) (Jacksons 2010) (Laksmiwati et al. 2017). Design principles to ensure the long-term reliability of DWIs have not been studied. Research to develop these design principles contributes to the scientific body of knowledge.

Different starting points or theoretical paradigms can be used to develop design principles for systems that operate in the SES and in the STS. Resilience is used very often in the STS literature and in the SES literature to address the dynamics and developments of complex systems and the restoration after threats (Biggs et al. 2015) (Folke 2016) (Uday and Marais 2015) (Folke et al. 2010) (Folke 2006). Resilience fits well with our objective to support strategic decision making in view of safeguarding the reliability of water supply under changing circumstances. This paper, therefore, answers the following main research question: How can resilience be used effectively to develop design principles for the design of WRs of DWIs?

\section{Approach}

First, resilience was explored in-depth (section 3). In literature, resilience is used in different systems like the SES, the STS, organisational systems and in psychology and sociology. Resilience worked out in a specific system cannot simply be used in another system, because the application of resilience depends, among others, on the system's operational environment and the specific disruptive event (Uday and Marais 2015) (Olsson et al. 2015) (Bowd et al. 2015). The literature study provided useful, yet general, building blocks for our decision support framework.

The general building blocks were then used to develop design principles for WRs. To this extent, the differentiating characteristics of the WRs were studied. The function of WRs is to 
deliver water for the production of drinking water. The amount of water that is needed at different moments, the quantity, is a characteristic of WRs. The quality of the water of WRs determines the needed purification in the treatment process to comply with the legal drinking water standards, which can be very expensive, and this makes water quality also a characteristic of WRs. WRs extract water that can cause damage to agriculture or nature. Space needed for WRs itself and the protection of WRs cannot be combined with some other activities. These environmental impacts are also a characteristic of WRs.

In addition to these specific characteristics it was explored whether there were other dimensions that had to be taken into account to get a complete overview of possible design principles, such as different system scales (one WR or a network of WRs), and various social and technical aspects. The characteristics and dimensions are discussed in section 4 (section 3 in the manuscript is not correct and has to be section 4).

Subsequently, the characteristics and dimensions of WRs were combined to develop the water resources design principles (WR-DP) framework, by adapting the generic building blocks using these characteristics and the dimensions. The resulting WR-DP framework is described in section 4.

The framework was then operationalized in section 5, by applying the WR-DP-framework to a case of Vitens, a DWI company in the Netherlands. To test the framework the evaluation criteria reliability, validity and generalization were used, as operationalized by Morse (2015) and Maxwell and Chmiel (2014).

Generally, any evaluation of the application of a framework depends on the experience and knowledge of practitioners and researchers. Experience and knowledge can lead to more specific strategies but can also affect the results due to bias of experienced participants.

The first author of this article was one of the team members who developed the strategies for WRs, the subject of the case, and he was involved in the development of the WR-DPframework, the application of this framework and its evaluation. Although several years have passed between these activities, and both times the activities were done by a team of experts and management, this may have biased the results. However, by explicitly addressing what we evaluated and how we did this, we mitigated this risk.

The conclusions and recommendations are presented in section 6 .

\section{Resilience Enhancing Design Principles}

Resilience describes how to maintain services or recover after a threat (Uday and Marais 2015) (Jackson and Ferris 2012). There are different possibilities to respond to threats and that makes that resilience is a collection of different concepts which contribute in different ways to maintain services or to recover after threats (Uday and Marais 2015) (Jackson and Ferris 2012). For these different concepts design principles are available to enhance the resilience. In this study these design principles are called resilience enhancing design principles (REDP). These REDPs were used as building blocks to develop design principles for WRs. The REDPs can be divided into attributes based onto what the REDPs achieve. For example, the REDP "redundancy" achieves to survive a threat, while the REDPs "reducing complexity" and "repairability" achieve to increase the ability to adapt to a threat. Jackson and Ferris (2012) have distinguished four attributes: capacity (ability to survive a threat), flexibility (ability to adapt to a threat), tolerance (ability to degrade successfully in the face of a threat) and cohesion (ability to act as a unified whole in the face of a threat).

A compilation of REDPs that are applied in STS is made by Jackson and Ferris (2012) (Table 1). 
Table 1 Resilience Enhancing Design Principles divided in four attributes (capacity, flexibility, tolerance and cohesion) (based upon Jackson and Ferris 2012)

Resilience Enhancing Design Principles for Engineered Systems

\begin{tabular}{llll}
\hline Capacity & Flexibility & Tolerance & Cohesion \\
\hline Absorption & Reorganization & Localized capacity & Internode interactions \\
Physical redundancy & Human-in-the-loop & Drift correction & Reduce hidden interactions \\
Functional redundancy & Reduce complexity & Neutral state & \\
Layered defence & Repairability & & \\
& Loose coupling & & \\
\hline
\end{tabular}

Explanation of the REDPs and the attributes mentioned in Table 1, from Jackson et al (2012)

Capacity: ability of a system to survive a threat

- Absorption: the capability to absorb magnitude of threats.

- Physical and functional redundancy: the presence of alternatives (physical or functional) to perform critical tasks.

- Layered defence: the presence of two or more independent principles addressing vulnerabilities of a system.

Flexibility: ability of a system to adapt to a threat

- Reorganization: the possibility of a system to change its organization in the face of a threat.

- Human-in-the-loop: the principle that humans are in the loop when there is a need for human cognition.

- Reduce complexity: the principle that systems are not more complex than necessary.

- Repairability: the capability to be brought up to functioning in a specified period of time.

- Loose coupling: the ability to reduce the impact of failures propagating from one component to the next in a system.

Tolerance: ability of a system to degrade successfully in the face of a threat

- Localised capacity: the capacity to distribute the functionality through various nodes supporting the functionality if a single node of that system is destroyed or damaged.

- Drift correction: the possibility to take mitigating or corrective measures if a system is drifting towards the boundary of resilience.

- Neutral state: the possibility to delay -before actions have to be taken- to have time to survey the situation.

Cohesion: ability of a system to act as a unified whole in the face of a threat

- Inter node interactions: the capability of every node to communicate with the other nodes, including the management and control of information.

- Reduce hidden actions: the principle that potential harmful interactions between nodes of the system are reduced.

We will use this set of REDPs for the development of our WR-DP framework.

\section{Developing Design Principles for Water Resources}

The translation of the generic design principles, described in section 3, to a specific framework of design principles for WRs requires more detailed knowledge about the characteristics of WRs. The characteristics, like for example the water quantity or the water quality, lead to different design principles.

First, the relevant characteristics of WRs are discussed and after that, the relevant framework dimensions are discussed. In section 5 the framework is operationalised.

\subsection{WRs Characteristics}

The objective of WRs in the production of drinking water is to deliver the water for drinking water production. To guarantee the drinking water supply now and in the future, it is important 
that there is always enough input of water. This makes the availability of water, indicated as quantity, an important characteristic of WRs. The quality of the water of WRs determines the treatment that is necessary to produce save drinking water. WRs with water that hardly needs to be treated is much cheaper than water with many pollutants, requiring a complex and expensive treatment process. Changes in water quality are also complex in the purification. It can be cheaper and less risk full for the public health to use WRs at a large distance from the demand location which is easy to treat, but having higher transportation costs, than difficult to purify water from WRs at a close distance (de Moel et al. 2004). This makes that water quality, in addition to water quantity, also determines the architecture of the infrastructure.

Where the water is extracted is also relevant in the characterisation of WRs as it is related to the impact on environmental systems. The extracted water can cause drought in vulnerable ecological systems, subsidence of soil and houses and economical losses in agricultural areas, due to a lower crop yield as a result of moisture deficiency. The environmental impact (EI) is the third characteristic as it constrains the amount of water that is available for WRs. If the EI is too high in the opinion of other stakeholders, the extraction is not tolerated. For the design of WRs it is important to take care of the EI, the quality of the extracted water and the quantity of the WRs.

\subsection{Framework Dimensions}

WRs can be managed by designing and realising a technical construction for a single WR, but it is also possible that multiple WRs are designed to work together. For example, by combining multiple different WRs, other WRs can extract more water if there is a contaminant in one of the WRs, or if one of the WRs has not enough water, or if the EI of one of the WRs is not acceptable for stakeholders. The system scale at which a manager seeks solutions, determines the options available for addressing the three key characteristics (water quality, water quantity, environmental impact). Therefore, we distinguish a system scale dimension in our framework, ranging from a single WR to a network of WRs.

Another relevant distinction is between technical options and social (behavioural) options (or 'management' according to Biggs et al. (2015)). Both offer solutions to the manager for safeguarding quality, quantity and EI. For example, a technical option is to use two independent pumps, so a spare pump can take over the functioning of the other in case of a pump failure. In the social part management must guarantee the availability of the pumps when they are needed most. For example, managers prevent that maintenance of a pump is done during an expected peak in the water demand. Therefore, we distinguish a dimension 'class' in our framework, spanning social and technical solutions.

\subsection{Water Resource Design Principles Framework}

By combining the two dimensions, system scale and class, four different quadrants are created for which design principles can be made: 1) individual WR and social aspects, 2) individual WR and technical aspects, 3) network of WRs and social aspects 4) network of WRs and technical aspects. Each of the characteristics, water quantity, water quality and EI, needs to be addressed within each quadrant. The result, our water resource design principles framework (WR-DP-framework) is presented in Fig. 2. The WR-DP-framework with four quadrants, and three characteristics, lead to 12 design spaces, each with a set of resilience enhancing design principles. In Table 1, fourteen REDPs were presented, so theoretically this would lead to 168 (12 times 14) different design principles. 


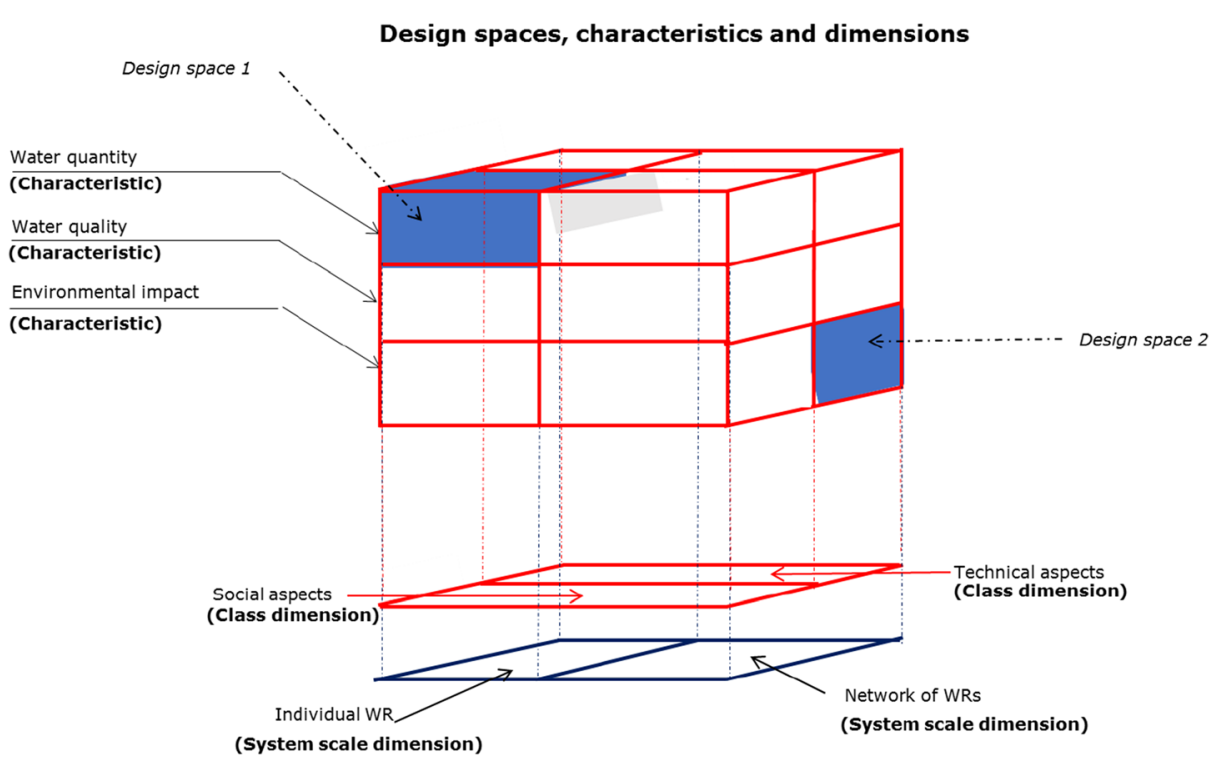

Fig. 2 Water resource design principles framework (WR-DP-framework)

\subsection{Design Principles for WRs}

Each design space is enclosed by one characteristic and two dimensions, a class dimension and a system scale dimension. To develop specific design principles for each design space, the REDPs belonging to that design space were used in the following way: the three characteristics and two dimensions are integrated in the generic REDPs by mentioning the characteristics and the dimensions as topics to which the generic REDPs are applied.

This has been illustrated for two design spaces (the blue design spaces in Fig. 2).

Design space 1 is about the social aspects of an individual WR with respect to water quantity and design space 2 about technical aspects of a network of WRs for environmental impact.

The illustration is done for functional redundancy: the capability to absorb magnitude of threats, and humans-in-the-loop: the principle that humans are in the loop when there is a need for human cognition.

\subsubsection{Functional Redundancy}

Design space 1: The WR is managed in such a way that functional alternatives are available when necessary; for example, working instructions are made and implemented to guarantee the availability during operations in a high-water demand period. In the instructions the areas are described where the water pressure can be lowered to reduce the needed amount of water and how and when the communication department starts to ask customers to save water.

Design space 2: EI of WRs in a network has functional alternatives; for example, if the EI of a WR is not accepted by stakeholders (too much drought), technical constructions are available that can reduce the EI like reducing drought by setting up the surface water level with a weir or pumping surface water to the drought area. 


\subsubsection{Humans-in-the-Loop}

Design space 1: The water quantity of a WR is managed in such a way that humans are in the loop if necessary; for example, working instructions are available and operators know who is in charge to take over control and when that has to be done.

Design space 2: EI of WRs in a network has humans in the loop; for example, the drought due to the extraction of groundwater is reduced by supplementing surface water from an infiltration pond. This process can function automatically, but it is also possible to take over control by humans. The control is taken over if the quality of the water in the pond is contaminated.

\section{Operationalization of the Water Resource Design Principles (WR-DP) Framework}

The developed WR-DP framework was applied in a real-world case of a DWI company in the Netherlands, Vitens, and the results were evaluated on their reliability, validity and generalizability. The case has two steps: 1) evaluation of the long-term vision on WRs of 2016 (section 5.1) and 2) developing design principles for the long-term vision on WRs of 2020 (section 5.2). Finally, the framework and its application were evaluated (section 5.3).

\subsection{Evaluation of the Long-Term Vision on WRs of 2016}

Vitens has made a long-term vision (Vitens 2016) -before the WR-DP-framework was developed- and in this plan Vitens described some strategies for managing the WRs, the Vitens Long Term Water Resources Strategies (Vitens-LT-WR-Ss). We aimed to identify any gaps in the Vitens-LT-WR-Ss by using the WR-DP-framework.

In 2015 and 2016 the strategy department of Vitens (Vitens 2016) developed the VitensLT-WR-Ss to guarantee the long term availability of water resources in two steps: 1) identification of risks and 2) developing strategies to mitigate those risks.

Risks that were identified:

1) Risks related to the availability of water and water resources

2) Risks related to the quality of water resources

3) External risks

Based on these risks, the Vitens strategy department formulated specific long-term strategies for WRs in workshops with managers and experts in the Vitens company, the Vitens-LT-WRSs (Vitens 2016). In the Vitens-LT-WR-Ss a distinction was made between management strategies (Vitens management LT-WR-Ss) and system strategies (Vitens system LT-WR-Ss). Elements of the Vitens management LT-WR-Ss are:

A. Stakeholder involvement with (potential) pollution problems and defining measures to prevent, mitigate or remove (potential) pollutions in WRs

B. Knowledge of future water demand developments and changes in time (e.g. peaks during hot and dry periods)

C. Awareness for possible external human and natural threats and changes in the environmental impact of the WRs (for example due to climate change) 
Elements of the Vitens system LT-WR-Ss are:

1) Diversity in the types of water resources, to prevent that quantity changes in one WR affect all WRs

2) Sustainable combinations of a WR with other activities

Then an analysis was done to find possible differences between the Vitens LT-WR-Ss and the strategies resulting from the application of the WR-DP design framework. The analysis gave the following insights:

\subsubsection{Scale dimension: individual WR versus network of WRs.}

In the Vitens LT-WR-Ss "individual WR" and "network of WRs" are not explicitly distinguished. Only one strategy of the Vitens system LT-WR-Ss is explicitly about the network. The other strategies of the Vitens system LT-WRs and all strategies of Vitens management LT-WRs can be related to an individual WR but also to a network of WRs. A clearer distinction between individual WR and a network of WRs is important as they lead to different strategies. For example, flexibility in the extraction can be organised by using WRs that can easily change in extraction amount without environmental impact that is not acceptable for stakeholders, but flexibility can also be organised by connecting all WRs with pipes with each other.

It is also noteworthy that most of Vitens LT-WR-Ss is related to REDPs of the attribute "capacity", some to the attribute "flexibility" and none to the attributes "tolerance" and "cohesion".

Conclusion: The Vitens LT-WR-Ss would have had a more comprehensive overview of possible strategies if the WR-DP-framework was used to develop strategies for an individual WR and a network of WRs.

\subsubsection{Class Dimension: Social Versus Technical Aspects}

A distinction between management and system is made in the Vitens LT-WR-Ss, while the WR-DP-framework uses "social aspects" and "technical aspects". Management in the Vitens LT-WR-Ss has primarily a focus on the management tasks of management and employees of Vitens, the DWI company. This is probably because it was drawn up in internal Vitens sessions but could also be due to the word "management". We expect that using "social aspects" would have invite participants of the workshops to look at more aspects than management, like the activities of government and other stakeholders.

System has similarities with technical aspects, but the strategies in the Vitens LT-WR-Ss includes a combination of technical and social aspects. We argue that "social aspects" versus "technical aspects" is a sharper distinction than "management" versus "system" and that the Vitens LT-WR-Ss would have had more sharply specified strategies if the framework was used.

Conclusion: The Vitens LT-WR-Ss would include not only management aspects, but also social aspects of other stakeholders if the WR-DP-framework was used. The strategies of the Vitens LT-WR-Ss would probably have been formulated more sharply if the WR-DP-framework was used. 


\subsubsection{Characteristics: Quantity of WR, Quality of WR and the El}

Quantity of WR, quality of WR and the EI are important issues for drinking water companies, so it is not surprising that they are addressed in the Vitens LT-WR-Ss. For example, quantity is addressed in example $b$ of the Vitens management LT-WR-Ss about insight in the future water demand that determines the needed water from WRs in time. Quality is addressed in example a of the Vitens management LT-WR-Ss about preventing, mitigating or removing (potential) pollutions in WRs and EI in example $\mathrm{c}$ of the Vitens management LT-WRs about natural threats and changes in the EI of WRs.

However, a systematic analysis based on the different characteristics is missing and therefore strategies are missing. For example, the Vitens LT-WR-Ss does not contain strategies dealing with the EI like preference for areas that are not vulnerable for changes in the water balance or preference for areas where the environmental impact can be mitigated or restored. Also, design principles on water quality and water quantity are missing, like the design principle to extract clean water with a constant and predictable quality and the design principle to mitigate the impact of shortage of water or water quality problems.

Conclusion: The Vitens LT-WR-Ss would have had a more comprehensive systematic overview of strategies for the three characteristics if the WR-DP-framework was used.

\subsection{Developing Measures to Solve Bottlenecks}

Due to long periods with hot weather in the summers 2018, 2019 and 2020, the drinking water demand in the Vitens area was much higher than in recent decades. The result was that permits of water resources on a monthly and annual basis were exceeded and Vitens had problems to deliver the desired amount of water. Stakeholders complained about the drought damage they suffered from the water extractions and objected to the permits being exceeded. The regional differences turned out to be large, because while there were many bottlenecks in one area (dry sand areas vulnerable for drought), there was enough water available for the different stakeholders in other areas.

Governments and Vitens wanted to avoid this situation occurring again and Vitens was asked to take measures to solve these bottlenecks. The WR-DP-framework was used to develop these measures (Vitens 2020) (Vitens 2019a, 2019b).

Central question was how to make the WRs future proof. Future proof WRs are defined as WRs that are able to handle high water demands with a water quality that has known fluctuations during years so the treatment can be can designed on this known and varying quality and the environmental impact is acceptable for all stakeholders.

Measures to make the WRs future proof were developed in a workshop in four steps:

1) Workshop participants were divided in three groups: water quantity, water quality and environmental impact;

2) Half of the participants of each group had to develop social measures and the other half technical measures;

3) The task in the first workshop was to develop measures for individual WRs and the task in the second workshop was to develop measures for a network of WRs. In both workshops all REDPS had to be discussed for possible measures; 
4) Presenting the results of all groups to each other and identifying possibilities to integrate the different measures. For example, by reducing the water demand by customers the environmental impact will reduce, and the quantity problem will also get smaller.

The result was that Vitens started a program "water for Now and Later" which has five projects which are related and have a focus from the short term (next year) to the long term (change of the total system). The program has project managers for the different projects, but in the program committee these project managers work with strategy experts and stakeholders together to identify bottlenecks, overlaps, chances and improvements. The program committee reports to a strategic management steering group. On project level, on program level and on management level the progress is discussed with external stakeholders.

\subsection{Evaluation}

The development of the framework (section 4) and the application of the WR-DP-framework (sections 5.1 and 5.2) in the case were evaluated on reliability, validity, and generalizability:

- Reliability: are the same results obtained if the study was repeated?

The evaluation guided by this question was done by analyzing possible causes to get other results in the case.

- Validity: are the descriptions recognizable by other users?

The evaluation for this question was done by analyzing the acceptance of the results of the application of the framework by experts, management, and the board of Vitens.

- Generalization: are the principles usable for other (DWI) systems?

The evaluation for generalization was done by comparing the characteristics and dimensions of the case with other systems. If characteristics and dimensions are the same, it can be expected that the framework is also applicable in that system.

\subsubsection{Reliability}

Development of the Framework The case showed that characteristics and dimensions were useful to get a comprehensive systematic overview and that they were helpful to develop a program to make WRs more future proof. Based on this we conclude that characteristics and dimensions are relevant for the WR-DP framework. Discussions with experts of the Vitens company and the case gave no reason to add other characteristics or dimensions.

The case also showed some strategies, like for example "developing knowledge and systematically working" and "stakeholder involvement" that are part of the Vitens LT-WR-Ss, but are missing in the WR-DP-framework. This can be the result of the use of REDPs of STS and as WRs are operating at the interface between STS and SES, it is interesting to investigate if the use of REDPs for the SES would lead to inclusion of this kind of strategies. 
Application of the Framework The results of the application of the WR-DP-framework is determined by the present-day context. For example, the droughts during the summers in 2018, 2019 and 2020 caused a higher focus on the availability of water than before, resulting in a program "water for Now and Later" The experience and knowledge of the teams also influenced the results.

Based on these, the context and experience and knowledge of teams working with the framework influences the results and it is recommended to check the results of the application of the WR-DP-framework periodically with different teams and working methods and with chances in the context.

\subsubsection{Validity}

The development and application of the framework are discussed together because they are strongly related with respect to the acceptance of the results by experts, management and the board of Vitens.

The use of the framework for an evaluation and for the development of measures is accepted by experts, management, and the board of Vitens. The results of the application of the framework are the basis for an expensive program with a major impact on the Vitens organizations and the stakeholders. The objective of the program is to reduce the drinking water consumption of households and industries, to remove WRs and replace them from drought vulnerable areas to more sustainable locations and to change the water management system. At present, the water management system is designed to drain rainwater as fast as possible to the sea, which is favorable for cultivating agricultural land. The aim of the program is to change the water management system towards a situation in which the water is retained more, and areas become wetter. This new situation is most of the time better for all water related activities, like WRs, nature and agriculture, due to the expected climate change.

The results also influence the Vitens research agenda. Vitens started for example a research project to investigate the possibility to make (groundwater) WRs more flexible in the amount of water that can be extracted, without exceeding the acceptable environmental impact (Vitens 2019a, 2019b).

The fact that the framework is used for an evaluation and to define measure illustrates that the framework, and the results that are obtained by applying the framework, are considered relevant and recognizable by experts, management and board in the Vitens company.

\subsubsection{Generalization}

All characteristics and dimensions of the WR-DP-framework are reflected in the case. This is also the case for other drinking water infrastructures that operate water resources, drinking water treatment facilities and a piping network for transport and distribution of drinking water. Based on this it is expected that the WR-DP-framework can be used for WRs planning and operation in all kinds of DWIs.

\section{Conclusions and Recommendations}

This paper discussed how resilience can be used to design water resources in such a way that they function in the desired way at present, but that the design also fits with an uncertain 
future, as good as possible. Generic resilience enhancing design principles, developed for social-technical systems, were used to develop water resource specific design principles. For that, the generic resilience enhancing design principles were specified by using three characteristics (water quantity, water quality and environmental impact) and two dimensions, system scale and class, that are relevant for water resources.

Combining these three characteristics and four quadrants of the dimensions lead to 12 design spaces, each with a set of resilience enhancing design principles: the water resource design principles (WR-DP) framework. Application of the framework in a case showed that the framework, and distinguished characteristics and dimensions are relevant and accepted by experts.

The application of the WR-DP framework in a case of drinking water company illustrated that the results are accepted, considered relevant and are recognizable by experts, management, and board in the Vitens company. The case also showed that the present-day context of a company could play a role and might bias the definition of risks and mitigation measures. Applying the systematic WR-DP framework regularly, will address most of this bias.

It is expected that the WR-DP-framework can also be applied in other drinking water infrastructures using WRs, as these DWI have the same characteristics and dimensions.

It is recommended to conduct further research to optimize the framework and the use of the framework. The framework is based on resilience enhancing design principles, developed for social-technical systems, but water resources of drinking water infrastructures are at the interface between the social-technical system and the social-ecological system. It is therefore recommended to investigate the application of resilience enhancing design principles, developed for social-ecological systems, in the WR-DP-framework.

Finally, the amount of theoretically different design principles (168) makes it difficult to choose and prioritize between these design principles. It is recommended to develop a process to guide this prioritization.

Data of Availability Not applicable (data and materials are freely available).

Authors Contributions All authors have contributed to the paper. The first author has written the paper and the two other authors reviewed and improved the manuscript several times.

\section{Compliance with Ethical Standards}

Ethical Approval All work is compliance with Ethical Standards.

Consent to Participate Not applicable.

Consent to Publish Authors and Vitens (case studies) give their permission to publish.

Competing Interests Not applicable.

Open Access This article is licensed under a Creative Commons Attribution 4.0 International License, which permits use, sharing, adaptation, distribution and reproduction in any medium or format, as long as you give appropriate credit to the original author(s) and the source, provide a link to the Creative Commons licence, and indicate if changes were made. The images or other third party material in this article are included in the article's Creative Commons licence, unless indicated otherwise in a credit line to the material. If material is not included in the article's Creative Commons licence and your intended use is not permitted by statutory regulation or 
exceeds the permitted use, you will need to obtain permission directly from the copyright holder. To view a copy of this licence, visit http://creativecommons.org/licenses/by/4.0/.

\section{References}

Agusdinata D, DeLaurentis D (2008) Specification of system-of-systems for policymaking in the energy sector. Integr Assess J Bridging Sci Policy 8(2):1-24

Bauer J, Herder P (2009) Designing socio-technical systems. Handbook of the Philosophy of Science. Philosophy of technology and engineering sciences 9:601-630

Biggs R, Schluter M, Schoon M (2015) Principles for Building Resilience; sustaining eceosystems services in Social-Ecological Systems. Cambridge University Press, Cambridge

Bowd R, Quinn N, Kotze D (2015) Toward an analytical framework for understanding complex social-ecological systems when conducting environmental impact analyses in South Africa. Ecol Soc 20(1):article 41

Bruijn Hd, Herder P (2009) System and Actor Perspectives on Sociotechnical Systems. IEEE Transactions on systems, man and cybernetics- part A: systems and humans 39(5):981-992

de Moel P, Verberk J, van Dijk J (2004) Drinkwater-principes en praktijk. Sdu uitgevers b.v, Den Haag

Doorn N, Gardoni P, Murphy C (2019) A multidisciplinary definition and evaluation of resilience: the role of social justice in defining resilience. Sustainable and Resilient Infrastructures, 4(3):112-123

Folke C (2006) Resilience: the emerge of a perspective for social-ecological system analyses. Global Environmental Change 16(3):253-267

Folke C (2016) Resilience (republished). Ecol Soc 21(4):44

Folke C, Carpenter S, Walker B, Scheffer M, Chapin T, Rockström J (2010) Resilience Thinking: Integrating Resilience, Adaptability and Transformability. Ecol Soc 15(4):20

Guidotti R, Chmieleweski H, Unnikrishnan V, Gardoni P, McAllister T, Lindt Jv (2016) Modeling the resilience of critical infrastructures; the role of network dependencies. Sustain Resilient Infratsruct 1(3-4):153-168

Herder PM, Bouwmans I, Dijkema GP, Stikkelman RM, Weijnen MP (2008) Designing Infrastructures using a complex systems perspective. J Des Res 7(1):17-34

Hollnagel E, Paries J, Woods D (2010) Resilience engineering in practice: a guidebook. Ashgate Publishing Company, Farnham

Jackson S, Ferris T (2012) Resilience Principles for engineered systems. Syst Eng 16(2):152-164. https://doi.org/ $10.1002 /$ sys. 21228

Jacksons S (2010) Architecting resilient systems; Accident avoidence and survival and recovery form disruptions. Wiley, Hoboken

Kloosterman R, van der Hoek J (2019) An integrated system approach to characterize a drinking water infrastructure system. Int J Crit Infrastruct

La Loggia G, Puleo V (2020) Floodability: A New Paradigm for Designing Urban Drainage and Achieving Sustainable Urban Growth. Water Resour Manag 34:3411-3424

Laksmiwati E, Cahyani R, Kloosterman R, Lips M, Jager Fd (2017) Moving Together Towards Resilient Water Supply for Semarang. Semarang, Indonesia: WaterWorX, Interception Phase II: project Plan

Markolf S, Chester M, Eisenberg D, Iwaniec D, Davidson C, Zimmerman R, Chang H (2018) Interdependent Infrastructure as Linked Social, Ecological and Technological System (SETSs) to adress Lock-in and Enhance Resilience. Adv Earth Space Sci 6:1638-1659. https://doi.org/10.1029/2018EF000926

Maxwell J, Chmiel M (2014) Generalization in and from qualitative analysis, in The SAGE handbook of qualitative data analysis; Flick. SAGE, Thousand Oaks

Mehrazar A, Massah Bavani A, Gohari A, Mashal M, Rahimikhoob H (2020) Adaptation of water resources system to water scarcity and climate change in the suburb area of Magecities. Water Resour Manag 34: 3855-3877

Mianabadi A, Derakhshan H, Davary K, Hasheminia S, Hrachowitz M (2020) A Novel Idea for Groundwater Resource Management during Megadroughts Events. Water Resour Manag 34:1743-1755

Morse J (2015) Critical Analysis of Strategies for Determining Rigor in Qualitative Inquiry. Qual Health Res 25(9):1212-1222

Olsson L, Jerneck A, Thoren H, Persson J, O’Byrne D (2015) Why resilience is unappealing to social science: Theoretical and empirical investigations of the scientific use of resilience. Sci Adv 1(4):1-11

Ostrom E (2007) A diagnostic approach for going beyond panaceas. PNAS 104:15181-15187

Ostrom E (2015) Governing the commons; the evolution of institutions for collective action. Cambridge University Press, Indiana (Canto Classics edition) 
Ostrom E, Gardner R, Walker J (2006) Rules, Games, \& Common-Pool Resources. Michigan: The University of Michigan Press. http://www.pres.umich.edu/titleDetailDesc.do?id=9739

Uday P, Marais K (2015) Designing Resilient Systems-of-Systems: A survey of Metrics, Methods and Challenges. Systems Engineering. 18(5):491-509. https://doi.org/10.1002/sys.21325

Vitens (2016) Veerkrachtig vooruit. Zwolle, Vitens

Vitens (2019a, oktober 29). Vitens innovates: abstraction. Opgehaald van Vitens innovates: https:// vitensinnovates.com/thema-winnen/. Accessed 29 Oct 2019

Vitens. (2019b, oktober 28). Water voor Nu en Later. Zwolle, intranet Vitens: Vitens.

Vitens. (2020). Langetermijnvisie op de Vitens-infrastructuur 2020-2050: Water voor $\mathrm{Nu}$ en Later. Zwolle: Vitens.

Walker W (2000) Policy analysis: A systematic approach to supporting policymaking in the public sector. J Multi-Criteria Decis Anal 9:11-27

Publisher's Note Springer Nature remains neutral with regard to jurisdictional claims in published maps and institutional affiliations.

\section{Affiliations}

\section{Ritsche A. Kloosterman ${ }^{1}$ - Jan Peter van der Hoek ${ }^{2}$ - Paulien Herder ${ }^{2}$}

Jan Peter van der Hoek

j.p.vanderhoek@tudelft.nl

Paulien Herder

P.M.Herder@tudelft.nl

$1 \quad$ Vitens, Zwolle, Netherlands

2 Delft University of Technology, Delft, Netherlands 